\title{
As concepções evolucionistas e criacionistas na formação de alguns graduandos em
}

\section{Ciências Biológicas}

\author{
The evolutionary and creationist conceptions in the education of undergraduate students of
}

\section{Biological Sciences}

Concepciones evolucionistas y creacionistas en la formación de algunos estudiantes de pregrado en

\section{Ciencias Biológicas}

\author{
Thiago de Ávila Medeiros \\ ORCID: https://orcid.org/0000-0003-2733-4150 \\ Faculdades São José, Brasil \\ E-mail: botanicatam@yahoo.com.br \\ Carlos Eduardo Lino da Silva \\ ORCID: https://orcid.org/0000-0001-6604-5912 \\ Faculdades São José, Brasil \\ E-mail: eduardolinobio@gmail.com \\ Lundoi Tobias Lee \\ ORCID: https://orcid.org/0000-0002-6055-3972 \\ Universidade Federal de Lavras, Brasil \\ E-mail: lundoilee@gmail.com \\ Nayla Souza Melo da Silva \\ ORCID: https://orcid.org/0000-0002-6599-7038 \\ Faculdades São José, Brasil \\ E-mail: naylamelloconta2013@gmail.com \\ Eline Deccache-Maia \\ ORCID: https://orcid.org/0000-0003-4770-3988 \\ Instituto Federal de Educação, Ciência e Tecnologia do Rio de Janeiro, Brasil \\ E-mail: eline.maia@ifrj.edu.br
}

\begin{abstract}
Resumo
A Teoria da Evolução mantém hoje o status de teoria unificadora e norteadora dos estudos e conceitos biológicos, e sua importância no estudo da biologia se evidencia nos parâmetros curriculares estabelecidos atualmente. Entretanto, com frequência a ciência evolutiva enfrenta uma resistência protagonizada, na maioria das vezes, por entidades religiosas, sobretudo as de vertente cristã. A área da educação se ressente dessa tendência e para entender o seu impacto através do presente trabalho, objetivou-se realizar uma pesquisa com estudantes universitários de Ciências Biológicas, a fim de verificar a possibilidade de interferência das vivências religiosas dos entrevistados, na aceitação ou assimilação do conteúdo das disciplinas e dos conceitos evolutivos. Além disso, foi objetivo verificar o nível de domínio desses estudantes sobre alguns mecanismos e conceitos evolutivos, assim como erros conceituais comumentes cometidos por estudantes. Os resultados obtidos solidam, em parte, com os estudos citados neste trabalho, identificando que as diferentes vivências religiosas dos alunos do curso de Ciências Biológicas podem interferir em suas concepções evolucionistas e, em médio prazo, ao assumirem o papel de professores de Ciências e Biologia, afetar suas futuras relações de ensino-aprendizagem com seus alunos.
\end{abstract}

Palavras-chave: Teoria da evolução; Criacionismo; Ciência; Religião.

\begin{abstract}
The Theory of Evolution today maintains the status of a unifying theory and benchmark of biological studies and concepts, and its importance is evident in the curricular parameters currently established. However, evolutionary science often faces a resistance, most often, by religious entities, especially those of the Christian aspect. The area of education resents this trend, and to better understand it impacts this work conducted a research with undergraduate students of Biological Sciences, in order to verify the possibility of interference of the religious experiences of the interviewees, with the acceptance or assimilation of the content of the disciplines and the evolutive concepts. In addition, it was necessary was to verify the level of knowledge of these students on some evolutionary mechanisms and concepts, as well as conceptual errors commonly made by students. The results obtained firm, in part, with the studies mentioned in this work, identifying those different religious experiences of students of the Biological Sciences course can interfere in their evolutionary conceptions and, in the medium term, when assuming the role of Biology and Science teachers, affect their future teaching-learning relationships with their students.
\end{abstract}


Keywords: Theory of evolution; Creationism; Science; Religion.

\section{Resumen}

La Teoría de la Evolución mantiene hoy el "status" de teoría de unificación que nortea los estudios y conceptos biológicos, su importancia en el estudio de la biología evidenciándose en los parámetros curriculares actualmente establecidos. Sin embargo, la ciencia evolutiva a menudo se enfrenta a una resistencia protagonizada, con mayor frecuencia, por entidades religiosas, en especial las de vertiente cristiana. El área de educación resiente esta tendencia y, para entender su impacto, este trabajo llevó a cabo una encuesta con estudiantes universitarios de Ciencias Biológicas de las Facultades São José, con la finalidad de verificar la posibilidad de interferencia de las vivencias religiosas de los entrevistados en la aceptación o asimilación del contenido de las disciplinas y de los conceptos evolutivos. Además, se pretendía verificar el nivel de dominio de esos estudiantes en algunos mecanismos y conceptos evolutivos, así como los errores conceptuales comúnmente cometidos por los estudiantes. Los resultados obtenidos firma, en parte, con los estudios citados en este trabajo, identificando que las distintas vivencias religiosas de los alumnos del curso de Ciencias Biológicas pueden interferir en sus concepciones evolutivas y, a mediano plazo, cuando asuman el rol de profesores de Ciencias y Biología, afectar a sus futuras relaciones de enseñanza-aprendizaje con sus alumnos.

Palabras clave: Teoría de la evolución; Creacionismo; Ciencia; Religión.

\section{Introdução}

"E disse Deus: Façamos o homem à nossa imagem, conforme a nossa semelhança; e domine sobre os peixes do mar, e sobre as aves do céu, e sobre o gado, e sobre toda a terra, e sobre todo o réptil que se move sobre a terra." Gênesis $1: 26$

"O homem, com suas nobres qualidades, ainda carrega no corpo a marca indelével de sua origem modesta." Charles Darwin

As duas frases apresentadas nessa epígrafe podem resumir a dicotomia de correntes de pensamento acerca de uma das mais insistentes perguntas já feitas pela humanidade: de onde viemos? Pergunta motivadora, extremamente investigada pela ciência através de avançados estudos da evolução biológica, já tendo sido obtidos resultados e evidências amplamente aceitas pela comunidade científica. Entretanto, vive-se ainda tempos de controvérsias entre correntes religiosas e a ciência, no que tange a origem da vida. Essa não é uma simples discussão entre diferentes ideologias, mas uma histórica cadeia de eventos que culmina nesse cenário de embate.

Esse cenário se complexifica em tempos de pós-verdades geradores de movimentos que têm como fundamentação aspectos subjetivos e emocionais para explicar a realidade. Os argumentos aceitos são, na sua maioria, oriundos de grupos com os quais o sujeito se identifica ideologicamente e não pelo argumento em si. Como resultante, assistimos ataques à ciência, aos cientistas e aos seus espaços de produção como, por exemplo, as universidades. A pós-verdade se sustenta nas conviç̧ões e não em provas e demonstrações como a ciência.

Infelizmente, essa realidade adentra os mais diversificados espaços sociais. Isso nos leva a indagar qual seria a influência da vivência de uma confissão religiosa em alunos graduandos de Ciências Biológicas, área que hoje encontra na biologia evolutiva a teoria mais unificadora dos conhecimentos relacionados à vida? $\mathrm{O}$ estudo de caso aqui apresentado busca investigar, mesmo que preliminarmente, as atuais concepções dos estudantes de Ciências Biológicas de uma Instituição de Ensino Superior da cidade do Rio de Janeiro acerca do tema "evolução biológica".

No entanto, antes de partirmos para a apresentação dos seus resultados, faz-se necessário resgatar o histórico de acontecimentos que permeiam a teoria da evolução como conhecemos hoje e os movimentos antievolucionistas representados, principalmente, por iniciativas de algumas entidades religiosas. 


\section{Darwin e a Teoria da Evolução}

Segundo Ridley (2009), quando Charles Robert Darwin (1809 - 1882) finalmente divulgou sua obra prima "A origem das espécies", ele não tinha acesso aos primórdios estudos sobre herança genética, produzidos por seu contemporâneo Gregor Johann Mendel (1822 - 1884). Desta forma, a importância da seleção natural proposta em seu livro foi muito questionada, até que, em meados de 1920 - 1930, pôde finalmente ser demostrada em associação aos conhecimentos da herança mendeliana. Portanto, os dois principais eventos da história do pensamento evolutivo são a descoberta e publicação da teoria da evolução por meio da seleção natural proposta por Darwin e a síntese dos estudos de Darwin com os de Mendel, caracterizando a chamada Teoria sintética da evolução ou Neodarwinismo.

Na época de Darwin, a fixidez das espécies era crença geral, embora isso não significasse que ninguém tivesse questionado a ideia até então. Assim como fez Erasmus Darwin, avô de Darwin, alguns naturalistas e filósofos de até dois séculos antes da data da publicação da "Origem das Espécies" fizeram especulações sobre o transformismo das espécies. Alguns enciclopedistas também o fizeram, como Denis Diderot (1713 - 1784). Contudo, nenhum deles conseguiu elaborar uma ideia que pudesse hoje ser reconhecida como satisfatória para a explicação geral de como as espécies se modificam (Ridley, 2009).

Madeira (2007) cita que Jean-Baptiste Pierre Antonie de Monet (1744 - 1829), mais conhecido como Chevalier de Lamarck, além de utilizar primordialmente o termo "biologia", foi o primeiro a apresentar de fato uma consistente teoria transformista. Lamarck era um essencialista que acreditava na imutabilidade das espécies. Contudo, após trabalhar durante muitos anos com plantas, foi nomeado curador dos invertebrados e, graças ao seu trabalho sobre os moluscos da Bacia de Paris, ficou convencido da "transmutação" das espécies. Com isso, em 1809, apresentou ao público o trabalho Philosophie Zoologique, no qual explicava sua teoria, conhecida como Lei do Uso e Desuso.

Ridley (2009) também relata que Lamarck tinha dois mecanismos para explicar como as espécies se transformavam. O principal trata de uma "força interna", um tipo de mecanismo desconhecido que poderia levar o organismo a produzir uma prole um pouco diferente da original. Dessa forma, segundo Lamarck, quando essas diferenças tivessem se acumulado, no decorrer de muitas gerações, seria possível notar visualmente uma linhagem transformada que poderia ser caracterizada como uma nova espécie.

O segundo mecanismo proposto é justamente o largamente lembrado até hoje: a herança de caracteres adquiridos. Utilizando o famoso exemplo citado por Lamarck, o "esforço" que as girafas ancestrais realizaram para alcançar folhas mais altas fez com que sua prole tivesse o pescoço gradativamente aumentado. Mesmo que de forma errônea, Lamarck não foi o precursor da ideia de caracteres adquiridos. Já na Grécia antiga, Platão também discorreu sobre o assunto, porém, de forma filosófica. Contudo, é inegável a importância dos estudos de Lamarck como inspiração para os estudos evolutivos posteriores (Ridley, 2009).

Enquanto isso (1832 - 1837), Darwin viajava pelo mundo como naturalista, a bordo do Beagle. No ano seguinte ao término da viagem, observando a sua coleção de tentilhões coletados nas Ilhas Galápagos, notou que deveria tê-los catalogado por ilha, mas inicialmente imaginou que todos pertenciam à mesma espécie. Ao verificar as diferenças entre os espécimes coletados e descobrir que eles eram provenientes de ilhas distintas, Darwin começou a propor que essas variações, provavelmente, teriam origem em um tentilhão ancestral comum. Sua impressão foi similar às observações que fez de como as emas diferiam de uma região para outra da América do Sul. A partir dá, seus esforços se concentraram em construir uma teoria que respondesse não somente porque as espécies se modificam, mas também porque elas são bem adaptadas, ponto este que as ideias anteriores, como o Lamarckismo, haviam falhado, na concepção de Darwin (Futuyma, 2002).

Ainda de acordo com Ridley (2009), Darwin conclui que, por conta da luta pela vida, as formas que se encontram melhor adaptadas à sobrevivência deixam uma prole maior e de forma automática aumentam em frequência de uma geração 
para a outra. Da mesma forma que o ambiente muda frequentemente ao longo do tempo, diferentes variações de uma espécie estarão mais bem adaptadas a ele do que às formas anteriores, e continuamente terão sua frequência aumentada, em detrimento da frequência diminuída das variações menos adaptadas. Portanto, à medida que esse processo continua, ele acaba - nas palavras de Darwin - "por resultar na formação de uma nova espécie".

Segundo Futuyma (2009), em 1856, Darwin estava a trabalhar naquilo que seria o seu "grande livro", Natural Selection, que não chegou a ser concluído, pois, em junho de 1858, o naturalista Alfred Russel Wallace (1823 - 1913) enviou a Darwin um manuscrito intitulado "Sobre a tendência das variedades de se afastarem indefinidamente a partir do tipo original". Sustentado pelas coletas de espécimes biológicos da América do Sul e no arquipélago Malaio, Wallace concebeu, de forma independente, a seleção natural. Posteriormente, partes do ensaio escrito por Darwin foram apresentadas em conjunto com o manuscrito de Wallace em uma reunião da Linnaean Society de Londres, que, embora não tenha obtido a resposta esperada, culminou na publicação do "resumo" do grande livro de Darwin, em 24 de novembro de 1859, sob o título de "A origem das espécies por meio da seleção natural, ou a preservação das raças favorecidas na luta pela vida", que esgotou sua primeira edição em um dia e, além de revolucionar o estudo das ciências naturais, pôs em discussão uma controvérsia que dura até hoje.

A importância da ciência da evolução é justificada pela sua capacidade de explicar a unidade da vida, segundo a qual todas as espécies se originaram de ancestrais comuns ao longo dos últimos 3,7 bilhões de anos. Além de explicar as características adaptativas dos organismos influenciadas por questões ambientais, elabora, a partir de princípios gerais, explicações para as mais diversificadas características dos organismos conhecidos, de traços moleculares a aspectos comportamentais e ecológicos. Assim, a perspectiva evolutiva criada por Darwin abalou os fundamentos da Filosofia, deixou sua marca na Literatura e nas Artes, afetou de forma profunda a Antropologia e trouxe novas perspectivas ao significado de ser humano. De fato, poucas descobertas científicas tiveram um impacto dessa magnitude na história do pensamento humano (Futuyma, 2002).

Não será à toa, então, que é possível observarmos nas Orientações Curriculares Nacionais (OCN's) complementares aos Parâmetros Curriculares Nacionais do Ensino Médio ( $\mathrm{PCN}+$ ) a importância fundamental do estudo da evolução. De acordo com esse documento:

Um tema de importância central no ensino de Biologia é a origem e evolução da vida. Conceitos relativos a esse assunto são tão importantes que devem compor não apenas um bloco de conteúdos tratados em algumas aulas, mas constituir uma linha orientadora das discussões de todos os outros temas. O tema 6 dos PCN+ - origem e evolução da vida - contempla especificamente esse assunto, mas é importante assinalar que esse tema deve ser enfocado dentro de outros conteúdos, como a diversidade biológica ou o estudo sobre a identidade e a classificação dos seres vivos, por exemplo. A presença do tema origem e evolução da vida ao longo de diferentes conteúdos não representa a diluição do tema evolução, mas sim a sua articulação com outros assuntos, como elemento central e unificador no estudo da Biologia. (Brasil, 2006)

Do mesmo modo é possível verificar a importância inegável do estudo da evolução biológica para a Biologia nas Diretrizes Curriculares Nacionais para os Cursos de Ciências Biológicas (DCNCCB).

O estudo das Ciências Biológicas deve possibilitar a compreensão de que a vida se organizou através do tempo, sob a ação de processos evolutivos, tendo resultado numa diversidade de formas sobre as quais continuam atuando as pressões seletivas. Esses organismos, incluindo os seres humanos, não estão isolados, ao contrário, constituem sistemas que estabelecem complexas relações de interdependência. (Brasil, 2001)

Apesar da ênfase dada ao tema na formação escolar do indivíduo, há aqueles que negam a sua importância e fundamentação. Ao abordar os grupos que questionam a veracidade ou importância do estudo da evolução biológica, faz-se necessário identificar que nem sempre os motivos estão ligados a uma vertente religiosa, mas também a equívocos conceituais inerentes a informação do senso comum (Monteiro, Santos, Figueredo, de Mello \& Medeiros, 2019). 
Uma grande parcela dos desacreditados na teoria da evolução costuma citar a palavra "teoria" como causadora do conflito, justificando que não há veracidade nem comprovação nos estudos da evolução por se tratar de uma "teoria". Futuyma (2009) explica que quando os biólogos se referem à teoria da evolução, a palavra em questão é utilizada no sentido em que é adotado em toda a ciência, corroborado pela definição do The Oxford Inglês Dictionary: "hipótese que foi confirmada ou estabelecida por observação ou experimentação e é proposta ou aceita como justificativa dos fatos conhecidos; uma afirmação das leis, princípios ou causas gerais de alguma coisa conhecida ou observada". Sendo assim, ela não significa uma mera especulação ou hipótese sem fundamento. O conjunto de princípios que explica as mudanças evolutivas constituem uma teoria no mesmo sentido da "Teoria Atômica" na Química.

A teoria da evolução ainda é controversa porque uma parcela da população a percebe como incompatível com crenças religiosas, principalmente no que tange a origem da vida. O chamado movimento antievolucionista - ou oposição criacionista à evolução - possui voz muito ativa nos Estados Unidos e chegou a ameaçar o financiamento por órgãos federais para a pesquisa evolutiva, desconsiderando seu valor científico e suas inúmeras aplicações (Futuyma, 2002).

\section{Criacionismo}

Carvalho (2010), afirma que muitas das manifestações religiosas conhecidas no planeta propuseram variadas explicações de como a vida e sua diversidade se originaram. Dentre as vertentes criacionistas presentes nos países ocidentais, as que se destacam em maior importância no âmbito do debate "evolução x criação" são: 1) Criacionismo da Terra jovem explicação fundamentalista que interpreta a Bíblia de forma literal e afirma que a Terra possui apenas 10.000 mil anos, que todo o material orgânico foi criado em seis dias por Deus e que o dilúvio foi um dos fenômenos responsáveis pelos atuais aspectos geológicos; 2) Criacionismo da Terra antiga - explicação que aceita as evidências geológicas, mas prega com literalidade as ideias da Bíblia sobre a origem e diversidade da vida; 3) Criacionismo de Dia/Era - interpretam-se os seis dias da criação divina de forma que cada um deles corresponde a uma era geológica, tentativa de convergência entre os dados geológicos e os escritos bíblicos; 4) Evolução Teísta- fundamentada principalmente pelas crenças da igreja Católica, atribuindo a Deus a criação das formas vivas por meio da Evolução (adeptos dessa vertente acreditam em grande parte nas evidências científicas, mas reservando a Deus o papel de agente causal); 5) Design Inteligente - seus adeptos formularam uma hipótese de que tamanha diversidade e complexidade biológica devem ser provenientes de um "design", implicando a existência de um "designer" inteligente (Deus).

Futuyma (2002) cita que alguns clérigos ensinam sobre evolução e até fazem pesquisas na área. O Papa Joao Paulo II, em um documento enviado à Pontifícia Academia de Ciências do Vaticano em outubro de 1996, ratificou a validade da evolução biológica, confirmando ao mesmo tempo a validade espiritual dos ensinamentos da Bíblia. Portanto, considera-se que o Catolicismo e a vertente criacionista Evolução Teísta não interferem de forma importante nos movimentos antievolucionistas. A oposição mais contundente à teoria da evolução e o ensino da mesma é realizada em predominância pelo fundamentalismo protestante.

De acordo com Schünemann (2008), o fundamentalismo protestante baseia-se na inspiração verbal da Bíblia, tomando-a como verdade absoluta e considerando plausível a possibilidade de se descobrir "tudo" a partir da mesma. Dessa forma, a tendência criacionista "científica" busca confirmar o relato bíblico através de pesquisas científicas, geralmente norteadas pela tentativa de demonstração da universalidade do dilúvio e da impossibilidade da macro evolução. Assim, é possível agrupar os principais argumentos do "criacionismo científico" em três eixos principais: 1) a Bíblia pode ser considerada um livro de ciência; 2) o dilúvio foi universal e é capaz de explicar toda a coluna geológica e os fósseis contidos nela; 3) a evolução biológica é apenas uma "teoria" e não existe uma ancestralidade comum às espécies. 
Entretanto, alguns autores criacionistas reconhecem a microevolução de forma geral e até o conceito de alterações adaptativas que poderiam culminar na formação de novas espécies, mas sempre em escala microbiológica. Quanto aos demais processos evolutivos, persistem na opinião de que se trata apenas de especulação, sendo a principal crítica os estudos referentes à origem da vida (Schünemann, 2008).

\section{Evolução x criação: um debate possível?}

De acordo com Faria e Pereira (2009), dentre os movimentos criacionistas "científicos", os adeptos do Design Inteligente figuram em lugar de destaque no debate evolução versus criação, pois alegam que sua teoria provém de natureza científica e, portanto, merece ser considerada tão importante quanto a teoria da evolução, inclusive no que diz respeito às orientações curriculares para o ensino de Ciências. Entretanto, dificilmente são citados os padrões de referência que seriam utilizados para inferir se um determinado fenômeno é ou não impossível de ocorrer apenas por intermédio de processos naturais. Identifica-se também a carência de linhas condutoras para investigar a natureza do "designer" ou de que forma essa hipótese pode ser falseada. Segundo Carvalho (2010), dentre os países do Ocidente, os Estados Unidos aparecem em posição de liderança quanto à influência criacionista, havendo vários confrontos legais a níveis curriculares nas instituições de ensino do país.

A revista Época, em sua edição online de no 419 (2006), cita alguns episódios determinantes para a história do movimento anti evolucionista americano. Em 1923, o adventista do sétimo dia George McCready Price lança o livro The New Geology, que tinha como principal argumento o dilúvio universal. Segundo o livro, todas as características geológicas presentes hoje e os fósseis encontrados são consequências desse dilúvio. Em 1925, John Scopes, um jovem professor do ensino fundamental da cidade de Dayton, no Tennessee, foi condenado por lecionar a teoria da evolução, uma vez que a legislação estadual da época o proibia. A polêmica envolvida foi tamanha que o julgamento foi apelidado de The Monkey Trial e se tornou o primeiro a ser transmitido em cadeia nacional de rádio. Sua história também foi contada através de uma peça e um filme, Inherit the Wind -"O Vento será a sua herança", no título em português. Em 1935, foi fundada a Religion and Science Association (RSA), que tinha o intuito de usar dados científicos para corroborar os escritos bíblicos. Após dois anos, alguns membros fundaram uma vertente mais radical, a Deluge Geology Society (DGS), que apoiava a Teoria do Dilúvio. Em 1941, foi fundada a American Scientific Affiliation (ASA), que tentava se apresentar como organização científica, exigindo que seus associados tivessem credenciais científicas legítimas e não concordava com a teoria do dilúvio universal.

Já em 1961, o engenheiro Henri Morris lança o livro The Genesis Flood, em coautoria com John C. Whitcomb, resgatando a já debilitada Teoria do Dilúvio de George McCready Price; unem-se ao bioquímico Duane Gish, da Universidade de Berkeley, e criam uma comissão antievolucionista no interior da ASA. Em 1963, Morris e Gish declaram a independência da comissão liderada por eles sob a sigla CRC (Creation Research Commitee), que logo mudaria seu nome para CRS (Creation Research Society) e, embora de caráter mais fundamentalista que a ASA, mantém a estratégia de só aceitar cientistas como membros.

No ano de 1974, é lançado o livro de Morris Scientific Creationism, que foi concebido para ser o livro definitivo sobre a "ciência" do criacionismo e destinado ao uso nas disciplinas de Biologia das escolas públicas americanas. Na mesma época, Morris fundou o Institute for Creation Research (ICR); já em 1990, é fundado o Discovery Institute, em Seattle, considerado o quartel-general do Intelligent Design (ID). Em 1996, é lançado o livro Darwin's Black Box: the Biochemical Challenge to Evolution, de Michael Behe, no qual ele argumenta que tamanha complexidade bioquímica dos genes não pode ser explicada apenas por mecanismos de mutação e seleção natural. É considerado o livro base do ID. 
Holden (2005) e Mervis $(2005,2006)$ expõem em matérias publicadas na revista Science casos emblemáticos do debate entre evolução e o ID, demostrando a tensa situação em que vivem os Estados Unidos no que tange o ensino da evolução.

Em uma escola do distrito de Dover, Estados Unidos, onze pais de alunos propuseram que o design inteligente deveria ser ensinado como uma alternativa à teoria da evolução e, com uma votação de 6 a 3, tornaram essa escola a primeira do país a instruir seus professores a informar aos alunos "falhas" na teoria da evolução e indicar outras teorias que possam explicar a origem e diversidade da vida, entre elas o ID. Diante disto, alguns professores de Biologia se recusaram a propagar essas informações, o que fez com que dois dos principais administradores do distrito visitassem as escolas para ler uma declaração informando que a teoria de Darwin era "apenas uma teoria". Feito isto, eles indicavam aos alunos a leitura de alguns livros doados anonimamente às escolas, dentre eles o intitulado Of Pandas and People (Sobre Pandas e Pessoas) que explica a teoria do Design Inteligente. A discussão foi parar em um tribunal da Pensilvânia, Estados Unidos (Holden, 2005).

Após o evento ocorrido em Dover, a professora Jennifer Miller, que há 12 anos lecionava assuntos da Biologia, dentre eles a teoria da evolução, tomou uma atitude radical ao abandonar a sala de aula acompanhada por três de seus alunos do nono ano. Entretanto, não se tratava de um "abandono" a seus alunos, mas de uma resposta à ordem da diretora da escola, na qual os professores deveriam ler uma declaração que atacaria a teoria da evolução e explicaria que a complexidade da vida requer uma ação de um agente inteligente (ID). A declaração proibia ainda a discussão científica em sala de aula sobre a origem da vida, consignando que o tópico deveria ser visto por cada aluno, juntamente com suas famílias (Mervis, 2005).

A polêmica de Dover, Pensilvânia, tem fim "por hora" em 20 dezembro de 2005, quando o Juiz do Tribunal Distrital Federal John Jones III ordena que as escolas de Dover removam as menções à teoria do Design Inteligente do currículo de Ciências. Em sua decisão de 139 páginas, o Juiz menciona: "ID não é Ciência."; "Nós achamos que o ID falha em três diferentes níveis, e cada um deles é suficiente para impedir uma determinação de que o ID é Ciência: 1) O ID viola as regras básicas centenárias da Ciência, invocando e permitindo uma causalidade sobrenatural; 2) $\mathrm{O}$ argumento da complexidade irredutível emprega um sistema de dualismo artificial falho e ilógico; 3) Os ataques negativos realizados pelo ID à teoria da evolução tem sido refutados de forma recorrente pela comunidade científica" (Mervis, 2006).

Já no Brasil, de acordo com Schünemann (2008), a produção de material a respeito do criacionismo "científico" está associada geralmente às vertentes religiosas Batistas e Adventistas do Sétimo Dia, tanto em termos de instituição como de ações voluntárias. A quantidade ainda reduzida de material impresso produzido, sendo quase na totalidade traduzido de obras americanas, demonstra uma possível fragilidade do movimento no Brasil.

Entretanto, de acordo com Abrantes e Almeida (2006), o Brasil não está fora do circuito de acontecimentos do debate evolução versus criação. A Lei Estadual n ${ }^{\circ} 3.459 / 2000$ de autoria do ex-deputado Carlos Dias, sancionada em 14 de setembro de 2000 pelo então governador do Estado do Rio de Janeiro, Anthony Garotinho, instituiu o ensino religioso confessional nas escolas públicas do estado. Em entrevista realizada à revista ComCiência em 10/07/2004, o deputado estadual Carlos Dias, autor do projeto de Lei, deixa claro sua postura em relação ao assunto:

A questão do criacionismo vai depender de como cada religião aborda essa temática. Mas também, o evolucionismo de Darwin está totalmente superado. Não há razão para se combater o criacionismo da maneira como as pessoas colocam. (...) Ninguém acredita hoje que o homem evoluiu do macaco. Essa é uma tese mais do que surrealista. (...) Não existe uma prova efetiva do evolucionismo.

Pouco tempo após a realização de concurso público para provimento de professores, a fim de atender a Lei 3.459/2000, vários meios de comunicação da época fizeram referência à entrevista dada pela então governadora Rosinha Matheus, na qual ela afirma: "Não acredito na evolução das espécies", "Tudo isso é teoria" (Martins \& França, 2004). Com 
essa declaração, a governadora demonstrou total desconhecimento do caráter das teorias científicas e dos critérios metodológicos que norteiam sua aceitação (Abrantes \& Almeida, 2006).

Por fim, Carletti e Massarani (2011) citam uma pesquisa realizada pelo Instituto Brasileiro de Opinião Pública e Estatística (IBOPE) em 2004, sob encomenda da revista Época, publicada em 13 de janeiro de 2005, que tinha por objetivo mapear a concepção da população brasileira em relação ao criacionismo. A pesquisa revelou que $31 \%$ da população acredita que Deus criou o homem nos últimos 10 mil anos, e já na sua forma atual; $63 \%$ dos brasileiros acreditam que a espécie humana se desenvolveu ao longo de milhões de anos, entretanto, apenas $9 \%$ destes informam acreditar que não houve interferência divina nesse processo. Outros dados apurados pela entrevista demonstram que $89 \%$ dos brasileiros entrevistados concordam que o criacionismo deveria ser ensinado nas escolas e 75\% acham que o criacionismo deveria substituir a teoria da evolução no currículo escolar.

Percebe-se, portanto, diante dos resultados da pesquisa acima citada, que o Brasil possui grande influência criacionista, não só acerca da discussão sobre a origem da vida, mas com relação à estrutura curricular do ensino de Ciências.

\section{A Teoria Evolutiva e as relações de ensino-aprendizagem}

Tendo em vista a produção de material científico referente ao tema do ensino da evolução biológica, Amorim e Leyser (2009) apresentam em seu trabalho um levantamento realizado ante as últimas seis edições dos Encontros Nacionais de Pesquisa em Educação e Ciências (ENPEC). No levantamento foram identificados apenas trinta artigos - de um total de 2.127 apresentados nas respectivas edições do ENPEC - que traziam como tema central a evolução biológica para o ensino de Ciências, indicando, portanto, uma certa dificuldade em relação à produção desse tipo de material, muitas vezes explicada pela negativa em tratar de temas controversos e polêmicos, uma vez que, em alguns casos, o tema transcende a dimensão educativa do conhecimento científico e esbarra nas concepções religiosas dos alunos e professores.

Entretanto, mesmo o número reduzido de artigos identificados com o tema pôde mostrar que boa parte trata justamente dos conflitos entre o conhecimento científico, representado pelas teorias evolutivas, e as crenças religiosas, representadas, por sua vez, pela dificuldade de aceitação destas teorias.

Objetivando o foco do estudo para os graduandos em Ciências Biológicas, trabalhos anteriores demostram que muito frequentemente encontram-se falhas interpretativas, erros conceituais, ou até mesmo o uso de teorias incorretas para explicar processos evolutivos. De acordo com Bizzo, Almenida e Falcão (2007), em uma pesquisa realizada com estudantes de Biologia a fim de verificar o nível de conhecimento referente à evolução biológica, 35\% das respostas indicavam que os entrevistados creditavam processos evolutivos já conhecidos, tais como as pernas fortalecidas de patos domésticos, à Teoria do Uso e Desuso. Nossa pesquisa pretendeu conhecer um pouco mais a respeito.

\section{Metodologia}

Nossa pesquisa teve como ponto de partida a pesquisa bibliográfica cujo propósito foi identificar a natureza e o estado do problema no Brasil e no mundo a partir de relatos, informações, publicações e artigos das áreas de educação e ensino.

A etapa seguinte consistiu em uma investigação empírica associada aos instrumentos de coleta e análise de dados. Os sujeitos da referida pesquisa foram estudantes de Ciências Biológicas de uma Instituição de Ensino Superior, localizada na zona oeste da cidade do Rio de Janeiro. Todos os estudantes participantes desta investigação declararam que já cursaram a disciplina de Evolução na referida instituição.

As informações foram coletadas através da aplicação de um questionário, subdividido em duas partes, com perguntas abertas e fechadas. A primeira parte apresentava perguntas mais gerais, ou seja, de concepções mais holísticas acerca da teoria evolutiva e sua relação com os sujeitos da investigação, com perguntas iniciais, além daquelas para obtenção de dados sobre o 
perfil do respondente (idade, sexo, etc.), tais como "Possui/participa de alguma vivência religiosa?","O que você entende por evolução biológica?". Neste momento, pretendia-se avaliar de forma quali-quantitativa (Pereira, Shitsuka, Parreira e Shitsuka, 2018) as respostas dos alunos, recorrendo à análise textual dos conceitos por eles apresentados, e assim identificar dificuldades com os conceitos da biologia evolutiva.

A análise e categorização das respostas foram feitas a partir de bibliografia básica sobre o tema e foram classificadas como: satisfatórias (S), parcialmente satisfatórias (PS) ou insatisfatórias (I), quanto aos conceitos pedidos.

A segunda parte do questionário visava verificar o conhecimento dos entrevistados acerca de conceitos básicos da evolução biológica, assim como identificar equívocos comuns apresentados por alunos em relação aos mecanismos evolutivos. Foram apresentadas afirmações conceituais em biologia evolutiva e o investigado poderia marcar verdadeiro ou falso. Dessa forma, buscou-se quantificar quais conceitos apresentavam maior e menor grau de domínio dos estudantes participantes da pesquisa.

Os sujeitos da investigação foram devidamente informados quanto à garantia do anonimato de suas participações na pesquisa.

\section{Resultados e Discussão}

Foram entrevistados 20 estudantes, sendo 12 indivíduos do sexo feminino (60\%) e 8 do sexo masculino (40\%), com idades entre 20 e 54 anos. Todos foram categorizados quanto à informação solicitada no início do questionário, que questionava a vivência religiosa dos entrevistados. Com isso, foram obtidos os seguintes números: 8 sujeitos $(40 \%)$ informaram ser evangélicos (protestantes), 4 sujeitos (20\%) informaram ser católicos, 2 sujeitos (10\%) informaram ser espíritas (kardecista/matriz africana) e 1 sujeito (5\%) informou apenas "igreja" como resposta, não sendo possível identificar a vertente religiosa a que pertencia. Por fim, 4 sujeitos (20\%) informaram não possuir religião e 1 sujeito (5\%) declarou-se ateu.

\subsection{Abordagem quali-quantitativa}

A primeira parte do questionário proposto era composto por 3 perguntas discursivas, tendo como objetivo verificar os conceitos mais gerais e holísticos dos sujeitos acerca dos conceitos de evolução biológica, de "teoria científica" e aspectos de ensino-aprendizagem da T.E. e seu embate com a religiosidade.

As respostas foram analisadas e categorizadas de acordo com a bibliografia pesquisada anteriormente, e só então classificadas como satisfatórias (S), parcialmente satisfatórias (PS) ou insatisfatórias (I).

A seguir apresentam-se os dados obtidos por questão na Tabela 1 e algumas situações selecionadas para análise. 
Tabela 1. Resultados obtidos nas questões abertas.

\begin{tabular}{|c|c|c|c|c|}
\hline SUJEITOS & Q1. RELIGIÃO & $\begin{array}{l}\text { Q2. CONCEITO } \\
\text { EVOLUÇÃO }\end{array}$ & $\begin{array}{l}\text { Q3. CONCEITO } \\
\text { "TEORIA" }\end{array}$ & Q4. ENSINO DA T.E. \\
\hline $1-28 a F$ & Evangélica & Parcialmente Satisfatório & Insatisfatório & Parcialmente Satisfatório \\
\hline $2-22 a F$ & Evangélica & Insatisfatório & Insatisfatório & Parcialmente Satisfatório \\
\hline $3-20 a F$ & "Igreja" & Insatisfatório & Parcialmente Satisfatório & Parcialmente Satisfatório \\
\hline $4-41 a F$ & Espírita & Satisfatório & Satisfatório & Satisfatório \\
\hline $5-31 a F$ & Católica & Parcialmente Satisfatório & Satisfatório & Insatisfatório \\
\hline $6-23 a M$ & Espírita & Parcialmente Satisfatório & Satisfatório & Satisfatório \\
\hline 7 - 31a M & Católica & Insatisfatório & Parcialmente Satisfatório & Insatisfatório \\
\hline 8 - 35a M & Não Possui & Satisfatório & Parcialmente Satisfatório & Satisfatório \\
\hline $9-21 a \mathrm{~F}$ & Ateu & Parcialmente Satisfatório & Satisfatório & Satisfatório \\
\hline $10-21 a F$ & Evangélica & Insatisfatório & Insatisfatório & Insatisfatório \\
\hline $11-25 a F$ & Evangélica & Parcialmente Satisfatório & Insatisfatório & Insatisfatório \\
\hline $12-20 a \mathrm{~F}$ & Evangélica & Satisfatório & Satisfatório & Satisfatório \\
\hline $13-22 a F$ & Não Possui & Parcialmente Satisfatório & Parcialmente Satisfatório & Satisfatório \\
\hline $14-28 a \mathrm{M}$ & Não Possui & Satisfatório & Insatisfatório & Satisfatório \\
\hline $15-28 a \mathrm{M}$ & Evangélica & Satisfatório & Satisfatório & Satisfatório \\
\hline $16-26 a F$ & Evangélica & Parcialmente Satisfatório & Satisfatório & Satisfatório \\
\hline $17-54 a \mathrm{M}$ & Não Possui & Satisfatório & Insatisfatório & Insatisfatório \\
\hline $18-23 a M$ & Católica & Satisfatório & Insatisfatório & Satisfatório \\
\hline $19-26 a F$ & Evangélica & Parcialmente Satisfatório & Insatisfatório & Insatisfatório \\
\hline $20-31 a M$ & Católica & Satisfatório & Satisfatório & Satisfatório \\
\hline
\end{tabular}

Fonte: Autores.

\section{Questão 2. O que você entende por evolução biológica?}

Na questão 2 - o que você entende por evolução biológica? - consideramos satisfatórias as respostas que indicavam a ancestralidade das espécies, os mecanismos e processos evolutivos conhecidos, o papel da aleatoriedade das mutações em conjunto com as diversas pressões seletivas. Em resumo, a descendência com modificações, de diferentes linhagens a partir de ancestrais comuns.

Dos 20 sujeitos entrevistados, 8 responderam à questão de forma satisfatória demonstrando conhecimento de conceitos que permeiam a evolução das espécies. Destes, 2 sujeitos declararam-se evangélicos, 2 católicos, 3 sem religião e 1 espírita.

Dentre as respostas citadas acima, destacamos as do sujeito 4 (41 anos, espírita): "É o surgimento de novas características que conferem ao indivíduo melhorias ou vantagens na sua adaptação ao meio"; do sujeito 8 (35 anos, sem religião): "São processos naturais de especiação e seleção de indivíduos ao longo do tempo"; do sujeito 12 (20 anos, evangélico): "processo onde os indivíduos, com o passar do tempo vão adquirindo características que ajudam na adaptação 
ao meio"; e do sujeito 14 (28 anos, sem religião): "processos de surgimento e extinção de espécies ao longo do tempo geológico, tendo como fatores preponderantes a variabilidade genética e mutações elencadas pela seleção natural".

Responderam com conceitos considerados parcialmente satisfatórios 8 sujeitos, pois, apesar de apresentarem informações inerentes a T. E., estas se encontravam incompletas ou fora de contexto. Contabilizaram nessas respostas 4 sujeitos evangélicos, 1 católico, 1 espírita, 1 sem religião e 1 ateu.

Dentre essas respostas, destaca-se a dada pelo sujeito 13 (22 anos, sem religião), na qual o investigado, apesar de demonstrar conhecimentos sobre a T.E., infere equivocadamente sobre uma possível "necessidade" de um organismo se adaptar ao meio, dizendo que ele "precisa" se adaptar: "É quando o indivíduo precisa se adaptar ao meio para sobreviver, adquirindo caracteristicas adaptativas".

Por fim, 4 sujeitos responderam à questão 2 de forma insatisfatória, não apresentando conceitos definidos que pudessem ser aceitos no âmbito da ciência evolutiva, ou conceitos muito equivocados, errôneos. Desses sujeitos, 2 eram evangélicos, 1 era católico e 1 declarou-se participante de "igreja" apenas.

Uma das respostas colhidas na questão 2 trata do exposto pelo sujeito 2 (22 anos, evangélico): "A evolução ocorre quando ao passar do tempo o indivíduo adquire características devido ao uso excessivo, conforme a necessidade". Claramente, o sujeito credita a evolução das espécies à Teoria do Uso e Desuso.

Questão 3. De acordo como os seus conhecimentos, julgue a afirmativa a seguir: "A teoria da evolução não deve ser aceita com total credibilidade, uma vez que ainda se trata de uma teoria". Você concorda com essa afirmativa? Justifique.

Em relação à questão 3, consideramos satisfatórias as respostas contrárias à afirmativa, em que os alunos necessariamente indicariam a validade e o sentido das teorias em meio acadêmico/científico e assim, ratificando a credibilidade da T.E.

Dos sujeitos entrevistados, 8 responderam de forma satisfatória, demonstrando conhecimentos suficientes sobre a validade das teorias científicas e também aspectos da T.E. Destes, 3 sujeitos eram evangélicos, 2 católicos, 2 espíritas e 1 ateu.

Dentre as respostas consideradas satisfatórias neste item, destacamos como exemplos as citadas pelo sujeito 4 (41 anos, espírita): "Não, a teoria é construída, experimentada e testada diversas vezes, não apenas aquilo que acha um único pesquisador"; pelo sujeito 6 (23 anos, espírita): "Não, a afirmativa se encontra incorreta por tratar a teoria como algo de baixa importância"; pelo sujeito 9 (21 anos, ateu): "Não, pois a teoria é cientificamente comprovada, possuindo evidências"; pelo sujeito 12 (20 anos, evangélico): "Não, pois a teoria é algo comprovado e não hipotético" e pelo sujeito 20 (31 anos, católico): "Não, as teorias científicas são pautadas em parâmetros , estudos e métodos científicos".

Quatro dos entrevistados responderam de forma parcialmente satisfatória, por vezes não entendendo plenamente o conceito de "teoria" no meio científico ou desmerecendo fatos inerentes a T.E. Neste item foram contabilizados 1 sujeito católico, 2 sujeitos sem religião e 1 sujeito que informou apenas "igreja" sobre sua religião.

Destaca-se a resposta dada pelo sujeito 3 (20 anos, "igreja"): "Não, pois apesar de ser uma teoria, há comprovações". É possível identificar nessa resposta que o entrevistado concorda com os preceitos da T.E. por existirem comprovações, no entanto, o sujeito considera a palavra "teoria" como um preceito para um possível descrédito.

Responderam esta questão de forma insatisfatória 8 sujeitos, utilizando o termo "teoria" como impeditivo para que a T.E. pudesse ser aceita, mesmo que em meio acadêmico. Dos sujeitos que assim responderam, temos 5 evangélicos, 1 católico, e 2 sem religião.

Algumas das respostas neste item refletem com clareza a falta de discernimento de alguns alunos quanto à importância e validade das teorias científicas, como é possível observar nas respostas do sujeito 1 (28 anos, evangélico): “ $E$ 
apenas uma teoria, não uma verdade; do sujeito 2 (22 anos, evangélico): "teoria pode ou não ser aceita, está relacionado a crença"; do sujeito 10 (21 anos, evangélico): "afirmativa que não possui fatos, não pode passar de uma teoria"; sujeito 19 (26 anos, evangélico) "algo para ter credibilidade, é preciso ser comprovado cientificamente" e do sujeito 14 (28 anos, sem religião): "esta teoria teve e ainda tem muita influência na biologia, mas deve ser posto à prova".

Questão 4. Hipoteticamente, um professor de Biologia que leciona para alunos do ensino médio, ao abordar o tema evolução das espécies, acrescenta ao conteúdo desse tema explicações religiosas para o surgimento da vida em nosso planeta, assim como a criação do ser humano. O professor alega que existe a importância de contrapor a teoria evolucionista com a vivência religiosa de seus alunos, ou até mesmo a sua própria religião, e assim, apresentar opções para que seus alunos possam debater e refletir. Você concorda com a abordagem desse profissional? Justifique:

$\mathrm{Na}$ questão 4 consideramos satisfatórias as respostas que reprovassem a conduta do profissional citado, expondo que a aula de Biologia pressupõe a exposição de conteúdo científico, e que adicionar a esse conteúdo explicações religiosas para o surgimento da vida e evolução das espécies pode causar dificuldades na assimilação do conteúdo proposto. Contudo, uma vez que a situação proposta não evidencia um conceito fechado, e sim uma atitude/opinião, as respostas favoráveis, mas que apresentassem uma argumentação satisfatória e que não ferissem os conceitos científicos poderiam ser enquadradas como (S) ou (PS).

Onze dos 20 sujeitos entrevistados responderam à questão de forma satisfatória, demonstrando o discernimento necessário de que a aula de Biologia deve priorizar o conteúdo científico, sem interferências de explicações religiosas. Desses 11, 3 sujeitos eram evangélicos, 2 católicos, 2 espíritas, 3 sem religião e 1 ateu.

Alguns dos exemplos de respostas consideradas satisfatórias colhidas neste item são as dadas pelo sujeito 8 (35 anos, sem religião): "Não, a educação adotada nas instituições de ensino devem ser laicas"; pelo sujeito 9 (21 anos, ateu): "Não, pois a evolução e o criacionismo são abordagens completamente diferentes"; pelo sujeito 12 (20 anos, evangélico): “Não, pois com a religião sendo acrescentada ao conteúdo, pode gerar confusão e não assimilação do conteúdo da proposta evolutiva" e pelo sujeito 20 ( 31 anos, católico): “Não, a ciência se distancia em muito da religião, e não devem ser abordadas juntas, cada qual em seu local e momento".

Entretanto, dos sujeitos citados acima, destaca-se a resposta dada pelo sujeito 4 (41 anos, espírita) que, apesar de concordar em parte com a iniciativa do professor, explica que os alunos devem saber discernir os diferentes tipos de saber: "Sim, não existe problema em se apresentar várias teorias. Mas, para tanto, o aluno deve ser capaz de reconhecer as várias versões do saber e diferenciar o pensamento cientifico, do pensamento filosófico por exemplo, utilizando-os de acordo com os espaços em que ele esteja inserido".

Apenas 3 sujeitos responderam este item de forma parcialmente satisfatória, por não explicarem exatamente a prerrogativa da centralidade do conteúdo científico na aula de Biologia ou por não indicarem caminhos de como a questão poderia ser abordada de forma a não interferir na assimilação do conteúdo. Contabilizaram neste item 2 sujeitos evangélicos e 1 "igreja".

Das respostas classificadas como parcialmente satisfatórias neste item, destacamos a dada pelo sujeito 3 (20 anos, "igreja"): "Não, pois apesar de estarem ligados, há alunos que não conseguem separar a religião da ciência".

Responderam à questão de forma insatisfatória 6 sujeitos, concordando com a postura do professor sem ressalvas ou justificando a importância da conduta descrita no enunciado por conta de sua vivência religiosa em particular. Dos sujeitos que assim responderam, temos 3 evangélicos, 2 católicos e 1 sem religião.

Destacam-se as respostas do sujeito 10 (21 anos, evangélico): "Sim, o professor tem o "dever" de passar essas informações. Como profissional é "inconstitucional" que ele haja de forma parcial"; do sujeito 11 (25 anos, evangélico): "Sim, 
nós evangélicos não concordamos com algumas teses da T.E., mas a respeitamos, e devemos respeitar todas as religiões" e do sujeito 5 (31 anos, católico): "Sim, devem ser passadas as informações para as crianças para que elas futuramente escolham a que fará parte de seu conceito".

De acordo com os resultados obtidos na primeira parte do questionário, é possível verificar uma grande quantidade de respostas insatisfatórias quanto aos conceitos pedidos (30\% do total de respostas), tendo em vista que os entrevistados são alunos de Ciências Biológicas, já concluintes na disciplina de evolução.

Dado o tamanho da amostra, podemos inferir primariamente dois principais fatores contribuintes para o número apresentado de respostas consideradas insatisfatórias. O primeiro trata-se do erro conceitual cometido por muitos alunos quanto ao significado e importância das teorias no meio científico, uma vez que das três questões abertas aplicadas nessa parte do questionário, o item 3 (conceito de teoria científica) concentrou a maior parte das respostas insatisfatórias.

Ficou demonstrado que a maioria dos sujeitos com respostas categorizadas como insatisfatórias nesse item, entende o termo "teoria" como algo sem validade, carente de fatos comprobatórios. Observou-se também uma recorrente confusão do termo "teoria" com o termo "hipótese".

O segundo fator observado seria a "possível" resistência de alunos religiosos - com uma pequena ênfase nos declarados protestantes - aos conceitos evolutivos. Apesar de ser assunto centralizador e ter abrangência a todas as áreas na Biologia, demonstra-se que a T.E. não é plenamente aceita, em especial por esses alunos, provavelmente por seu embate histórico e cultural com o criacionismo.

Das 18 respostas consideradas insatisfatórias nos três itens solicitados, 15 foram dadas por alunos que declararam alguma vivência religiosa, sendo 10 de alunos evangélicos, 4 católicos e 1 que informou apenas "igreja" como sua religião. As 3 respostas restantes são de alunos declarados sem religião.

Entretanto, é importante destacar que a amostra em questão tinha um número maior de declarados evangélicos do que os de outras religiões, dificultando, assim, inferir com certeza que a vertente evangélica tem maior restrição aos conceitos evolutivos do que as outras vertentes religiosas aqui citadas.

\subsection{Abordagem quantitativa}

A segunda parte do questionário consistia em 6 questões objetivas sobre conceitos e mecanismos evolutivos, nas quais os entrevistados poderiam marcar verdadeiro ou falso. Assim, objetivou-se quantificar quais conceitos apresentavam maior e menor grau de domínio dos alunos participantes.

Do total de 120 acertos possíveis no teste, dentre todos os entrevistados, obteve-se 26 respostas erradas perfazendo $21,7 \%$ de erros (Tabela 2 ). 
Tabela 2. Resultados obtidos nas questões fechadas.

\begin{tabular}{|c|c|c|c|c|c|c|c|}
\hline SUJEITOS & Q1. RELIGIÃO & Questão 5 & Questão 6 & Questão 7 & Questão 8 & Questão 9 & Questão 10 \\
\hline $1-28 a \mathrm{~F}$ & Evangélica & Certo & Certo & Certo & Errado & Errado & Certo \\
\hline $2-22 a F$ & Evangélica & Certo & Certo & Errado & Errado & Certo & Certo \\
\hline $3-20 a \mathrm{~F}$ & "Igreja" & Certo & Certo & Certo & Errado & Certo & Certo \\
\hline $4-41 a \mathrm{~F}$ & Espírita & Errado & Certo & Certo & Certo & Certo & Errado \\
\hline $5-31 a F$ & Católica & Errado & Certo & Errado & Certo & Certo & Certo \\
\hline $6-23 a \mathrm{M}$ & Espírita & Certo & Certo & Certo & Certo & Certo & Certo \\
\hline $7-31 \mathrm{a} \mathrm{M}$ & Católica & Errado & Certo & Certo & Certo & Errado & Certo \\
\hline $8-35 a \mathrm{M}$ & Não Possui & Certo & Certo & Certo & Certo & Certo & Certo \\
\hline $9-21 a \mathrm{~F}$ & Ateu & Certo & Certo & Certo & Certo & Certo & Certo \\
\hline $10-21 \mathrm{a} \mathrm{F}$ & Evangélica & Errado & Certo & Certo & Certo & Certo & Certo \\
\hline $11-25 a \mathrm{~F}$ & Evangélica & Errado & Certo & Certo & Errado & Errado & Certo \\
\hline $12-20 a \mathrm{~F}$ & Evangélica & Certo & Certo & Certo & Errado & Certo & Certo \\
\hline $13-22 a F$ & Não Possui & Certo & Certo & Certo & Errado & Certo & Certo \\
\hline $14-28 \mathrm{a} M$ & Não Possui & Certo & Certo & Certo & Certo & Certo & Certo \\
\hline $15-28 \mathrm{a} M$ & Evangélica & Errado & Certo & Certo & Certo & Certo & Certo \\
\hline $16-26 a \mathrm{~F}$ & Evangélica & Errado & Certo & Certo & Errado & Errado & Certo \\
\hline $17-54 a \mathrm{M}$ & Não Possui & Errado & Certo & Certo & Certo & Errado & Certo \\
\hline $18-23 a \mathrm{M}$ & Católica & Errado & Certo & Certo & Errado & Certo & Certo \\
\hline $19-26 a \mathrm{~F}$ & Evangélica & Errado & Certo & Certo & Certo & Errado & Certo \\
\hline $20-31 \mathrm{a} M$ & Católica & Certo & Certo & Certo & Certo & Certo & Certo \\
\hline
\end{tabular}

Fonte: Autores.

A seguir apresentam-se os conceitos em evolução que obtiveram maior e menor grau de domínio dos entrevistados.

As questões que obtiveram o máximo de acertos foram as de número 6 (100\% de acertos) e 10 (apenas 1 erro), que, respectivamente, traziam em seus conteúdos as evidências que hoje corroboram a T.E. e as atuais contribuições do estudo da genética e seu papel complementador no estudo da biologia evolutiva. Com isso, observamos um grau elevado de domínio dos entrevistados quando o assunto abordado está relacionado às evidências apresentadas pelos estudos da evolução, sejam elas os fósseis, a anatomia comparada de espécies ou o estudo filogenético.

Quanto aos conceitos e mecanismos evolutivos que apresentaram menor grau de domínio dos entrevistados, temos como exemplo as questões de número 8 (40\% de erros) e a questão 5 (50\% de respostas erradas). A questão 8 afirmava que o processo de seleção natural descrito por Darwin e Wallace caracterizava-se pela sobrevivência do indivíduo "mais forte" e a questão 5 indicava um processo lamarckista de adaptação de espécies, no qual os patos domésticos, por usarem as asas com pouca frequência e as pernas com muita frequência, adquiriram com o passar do tempo asas menos fortalecidas e pernas mais robustas, se comparados aos patos selvagens. Ermakov e Ermakov (2021), afirmam que Charles Darwin, o fundador da ideia da seleção natural, acreditava que essa seleção não se limitava exclusivamente à biologia: mudanças na linguagem, consciência e tecnologia também são adaptativas. A transmissão da cultura não é uma prerrogativa humana. Atualmente, existem diversas abordagens desenvolvidas para a compreensão da base biológica da evolução cultural.

Fica evidenciado, portanto, de acordo com os dados acima, que uma grande parcela dos alunos entrevistados tem dificuldades de assimilação quanto aos mecanismos determinantes para a evolução biológica, em especial a seleção natural. 
Os resultados obtidos com o questionário proposto acabam por validar, em parte, as informações trazidas no levantamento de literatura deste trabalho. Devido ao problema de discernimento sobre o real significado do termo "teoria" no âmbito científico, exposto por Futuyma (2002), alguns dos desacreditados na T.E. utilizam esse argumento para desqualificála. Citada também neste trabalho, a ideia suscitada pela declaração de Rosinha Matheus em 2002 (Martins e França, 2004; Abrantes e Almeida, 2006), na qual a então governadora do estado do Rio de Janeiro indica não acreditar na teoria da evolução e infere que tudo isso é "teoria", foi observada com clareza nas respostas dos sujeitos desta pesquisa ao item 3, no qual 8 dos 20 entrevistados referem-se ao termo "teoria" como algo sem validade científica e carente de comprovação.

Ainda de acordo com Futuyma (2002), a oposição mais contundente à teoria da evolução e ao seu ensino é realizada em predominância pelo fundamentalismo protestante. De forma semelhante, os resultados desta pesquisa demonstram que dentre as vertentes religiosas declaradas pelos sujeitos entrevistados, os ditos protestantes figuraram entre a maior parte das respostas consideradas insatisfatórias em relação aos conceitos evolutivos pedidos. Contudo, é necessário frisar novamente que esse dado pode ser discutível, uma vez que a quantidade de sujeitos declarados protestantes nesta amostra superava a quantidade de sujeitos de outras vertentes religiosas e de sujeitos não religiosos. De todo modo, o estudo aponta tendências.

Por fim, o levantamento realizado por Bizzo, Almenida e Falcão (2007), anteriormente citado neste trabalho, expõe que em uma pesquisa realizada entre estudantes de Biologia, 35\% dos alunos utilizam a teoria do uso e desuso para explicar processos evolutivos já conhecidos e já aqui mencionados, como as pernas fortalecidas de patos domésticos.

Na mesma direção, o estudo recente desenvolvido por Betti, Shaw e Behrend (2020) avaliou estudantes universitários de Ciências acerca da evolução biológica na vida. Os autores observaram a falta de aceitação da evolução biológica, mesmo com todas as evidências científicas que a apoiam, ressaltando que esse resultado pode ser bastante problemático em cursos de ensino superior que apresentam base biológica forte. Esses autores avaliaram a aceitação da evolução biológica ao longo de 344 anos, de estudantes de graduação de Ciências de cinco programas da Universidade de Roehampton, no Reino Unido. Os resultados obtidos foram que $9 \%$ dos alunos não aceitam a evolução por seleção natural, aumentando para 16\% quando se trata da evolução humana. Tanto a religião quanto o programa de estudo foram significativamente relacionados aos níveis de aceitação dos alunos. Em particular, a aceitação inferior foi associada às crenças muçulmanas ou às cristãs em Ciências Biomédicas, Nutrição e Programas de saúde quando comparados com Antropologia, Zoologia e Ciências Biológicas.

No estudo desenvolvido por Leão, Costa, Carvalho e Silva (2020), que avaliação a perspectiva de alunos do curso de Ciências Biológicas acerca da evolução biológica e criacionismo, sobre temas rela-cionados à teoria evolutiva (Acaso e Seleção natural) e criacionismo (Deus e Design inteligente). Aplicou-se o questionário, em uma amostra de 56 estudantes do $2^{\circ}, 4^{\circ}$ e $6^{\circ}$ períodos de graduação. Observaram que os alunos, em sua maioria, conseguem estabelecer uma relação de independência entre os temas, mesmo sendo religiosos, criando barreiras que delimitam os campos da ciência e da religião.

Ribeiro Junior et al. (2020) também desenvolveram estudos que abordaram a influência do ambiente educacional diante do pensamento evolutivo sobre a expressão da crença em Deus e na religiosidade entre os estudantes de nível médio. Os resultados obtidos indicam que a escola contribui e promove discussões sobre temas da atualidade, de interesse da comunidade ou referentes aos problemas sociais. Os autores afirmam que a qualidade no ensino não é fator exclusivo de influência na tomada de decisões dos alunos no que tange a explicações sobre a diversidade biológica. Possuir religião e praticá-la também pode ser um influenciador de significância no modo com que o estudante se relaciona com esse assunto.

\section{Considerações Finais}

A confluência dos resultados obtidos por este trabalho com os dados e informações de outros autores aqui também citados atestam para a conclusão de que as diversas vertentes religiosas vividas por alunos de Biologia podem interferir em suas concepções evolucionistas e, em longo prazo, em suas futuras relações de ensino-aprendizagem com seus alunos enquanto 
professores de Biologia. A recepção de conteúdos formativos não pode ser descolada da bagagem cultural trazida pelos alunos para dentro da sala de aula. A escuta e processamento das informações é feita a partir de um suporte anterior, que deve ser levado em conta no processo ensino-aprendizagem.

Observou-se que as concepções criacionistas desses alunos podem ser determinantes para a aceitação ou assimilação do conteúdo passado a eles nas disciplinas de evolução durante o período de curso em Ciências Biológicas.

Com isso, considera-se a possibilidade de elaborar novas estratégias de ensino afim de que esses alunos possam absorver o conteúdo necessário em evolução biológica, sem que em determinado momento tenham que colocar os conceitos evolutivos e suas concepções pessoais em posição de embate, gerando uma disputa dicotômica. Faz-se necessário que esses futuros professores de Ciências e Biologia tenham a consciência de que, independente de suas religiões, o conteúdo referente aos estudos da evolução biológica deve ser passado de forma integral, sem interferências de fontes que não sejam científicas de fato, e que seja dado à evolução biológica a importância norteadora e centralizadora em Biologia que ela detém, e que se encontra explícita nas Orientações Curriculares Nacionais (OCN’s), (PCN+) e (DCNCCB).

Por fim, foi possível também concluir, mediante os resultados observados, que um dos fatores determinantes para a dificuldade de assimilação dos conceitos evolutivos são os frequentes equívocos cometidos pelos alunos, principalmente relacionados ao discernimento do termo "teoria" no âmbito acadêmico e científico, e à Teoria do Uso e Desuso, proferida por Lamarck. Equívocos que muitas vezes podem ser evitados se houver estudo no campo epistemológico, que dará suporte para um melhor entendimento da T.E.

Contudo, é necessário considerar que o presente trabalho, ainda que realizado com reduzida amostra, apresenta uma realidade encontrada em muitos outros ambientes de formação docente e da literatura sobre o assunto. Os resultados aqui encontrados apontam para uma controvérsia que vem extrapolando as discussões entre vertentes religiosas e científicas, transbordando para o universo político mais abrangente e tornando os debates dicotômicos e, o que é pior, impondo a escolha de um lado apenas. O sujeito posto contra a parede, acaba fazendo escolhas privilegiando outros mecanismos que não a racionalidade, somando coro com os que defendem a pós-verdade.

\section{Referências}

Abrantes, P., \& Almeida, F. P. L. D. (2006). Criacionismo e darwinismo confrontam-se nos tribunais da razão e do direito. Episteme, 11(24), $357-402$.

Amorim, M. C., \& Leyser, V. (2009). A evolução biológica e seu ensino nos encontros nacionais de pesquisa em educação em ciências (ENPEC) The biological evolution and its teaching in the national meeting of research in science education (ENPEC).

Betti, L., Shaw, P., \& Behrends, V. (2020). Acceptance of biological evolution by first-year life sciences University Students. Science e Education, 1-15. https://doi.org/10.1007/s11191-020-00110-0

Bizzo, N., de Almenida, A. V., \& da Falcão, J. T.R. (2007). A compreensão de estudantes dos modelos de evolução biológica: duas aproximações students'understanding of biological evolution: two approaches. VI Encontro Nacional de Pesquisa em Educação em Ciências (ENPEC).

Brasil. Ministério da Educação. Diretrizes Curriculares Nacionais para os Cursos de Ciências Biológicas, 2001. Disponível no site: http://portal.mec.gov.br/cne/arquivos/pdf/CES1301.pdf Acesso em 18 de Março de 2021.

Brasil. Ministério da Educação. Parâmetros curriculares nacionais para o ensino médio PCN+ Orientações Educacionais Complementares aos Parâmetros Curriculares Nacionais. 2006. Disponível no site: http://portal.mec.gov.br/seb/arquivos/pdf/book_volume_02_internet.pdf Acesso em 18 de Março de 2021.

Carletti, C., \& Massarani, L. (2011). O que pensam crianças brasileiras sobre a teoria da evolução? Alexandria: Revista de Educação em Ciência e Tecnologia, 4(2), 205-223.

Carvalho, R. (2010). Avaliação dos futuros professores em Ciências Biológicas sobre a polêmica Criacionismo e Evolucionismo. 2010.115 p (Doctoral dissertation, Dissertação (Mestrado)-Universidade Federal de Goiás, Goiânia).

Ermakov, D., \& Ermako, A. (2021). Memetic approach to cultural evolution. Biosystems, 104378. https://doi.org/10.1016/j.biosystems.2021.104378

Faria, C., \& Pereira, G. (2009). Evolução versus Criacionismo: Um Debate Possível? Revista de Estudos Universitários-REU, 35(2).

Futuyma, D. J. (2002). Evolução, ciência e sociedade. São Paulo: Sociedade Brasileira de Genética. 
Research, Society and Development, v. 10, n. 7, e49410716931, 2021

(CC BY 4.0) | ISSN 2525-3409 | DOI: http://dx.doi.org/10.33448/rsd-v10i7.16931

Futuyma, D. J. (2009). Biologia Evolutiva. In Biologia Evolutiva (pp. 830-830).

Holden, C. (2005). ID goes on trial this month in Pennsylvania school case. Science, 309(5742), 1796-1796. DOI: 10.1126/science.309.5742.1796

Leão, I. M. S., Costa, F.J., Carvalho, G. S., \& Silva, H. M. (2020). Biological evolution and creationism from the perspective of biological sciences students. Góndola, Enseñanza y Aprendizaje de las ciencias (Bogotá, Colombia), 15(2). DOI: https://doi.org/10.14483/23464712.14656

Madeira, A. (2007). Fé e evolução: a influência de crenças religiosas sobre a criação do homem na aprendizagem da teoria da evolução com alunos do $3{ }^{\circ}$ ano do ensino médio (Doctoral dissertation, Dissertação apresentada ao Programa de Estudos Pós-Graduados em Ciência da Religião à PUC/SP. Orientador Prof. Dr. Eduardo Rodrigues da Cruz).

Martins, E; \& França, V. Rosinha contra Darwin. Época, N. 314 - Mai. 2004. Disponível no site: http:/revistaepoca.globo.com/Epoca/0,6993,EPT7315491664-1,00.html Acesso em 18 de Março de 2021.

Mervis, J. (2005). Dover teachers want no part of intelligent-design statement: a Pennsylvania school board has added" intelligent design" to its curriculum while simultaneously barring discussion of the origin of life. Science, 307(5709), 505-506.

Mervis, J. (2006). Judge Jones Defines Science--and Why Intelligent Design Isn't.

Monteiro, P. S., Santos, N. S., Figueredo, C. A., de Mello, T. M., \& de Ávila Medeiros, T. (2019). Ensino de biologia: a teoria da evolução na sala de aula. Ciência Atual-Revista Científica Multidisciplinar do Centro Universitário São José, 13(1).

Pereira, A. S., Shitsuka, D. M., Parreira, F. J., \& Shitsuka, R. (2018). Metodologia da pesquisa científica.

Ribeiro Junior, M. C., Korndörfer, C. L., Aragão, J. A., Martins, J. G. B. A., Holanda, J. dos S., \& Figueirêdo, L. S. (2020). Evolução biológica e criacionismo: vivência e discussão entre alunos do ensino médio. Research, Society and Development, 9(7), e16973640. https://doi.org/10.33448/rsdv9i7.3640

Ridley, M. (2009). Evolução. Artmed Editora.

Schünemann, H. E. S. (2008). O papel do "criacionismo científico" no fundamentalismo protestante. Estudos de religiao, 22(35), 64-86. 